\title{
A review of international and UK-based ethical guidelines for researchers conducting nontherapeutic genetic studies in developing countries
}

\author{
Shormila Roy Choudhury ${ }^{*, 1}$ and Leslie A Knapp ${ }^{1}$ \\ ${ }^{1}$ Department of Biological Anthropology, University of Cambridge, Pembroke Street, Cambridge, UK
}

Initiation and implementation of nontherapeutic genetic research projects, sponsored by developed countries and conducted in developing countries, requires careful consideration and awareness of procedures that ensure ethical research. This article reviews, and discusses controversies surrounding, the ethical principles established internationally and recommended by institutions in the UK for designing and implementing nontherapeutic genetic research studies. Before project commencement, the researcher should submit proposals to appropriate ethics committees and, wherever possible, seek guidance from experienced researchers. The researcher must also be aware of his/her responsibilities when conducting research with human participants. Responsibilities include respecting autonomy, privacy and confidentiality of participants, respecting social and cultural differences, providing appropriate information to participants, obtaining informed consent and offering appropriate compensation for participation. Finally, researchers involved in human genetics studies must also consider specific issues and public concerns when collecting biological samples. This includes using anonymised samples, considering future use of samples and ensuring confidentiality of results.

European Journal of Human Genetics (2006) 14, 9-16. doi:10.1038/sj.ejhg.5201497; published online 21 September 2005

Keywords: ethical guidelines; informed consent; developing countries; nontherapeutic

Introduction: health and research

Health research sponsored by developed countries, and conducted in developing countries, has contributed to the understanding, prevention and treatment of disease. However, some externally sponsored research in developing countries has led to irresponsible, and in some cases unethical, project initiatives. ${ }^{1}$ Many populations in developing countries lack access to regular health care, political power and familiarity with research. They may be exposed to risks and may not have

*Correspondence: Dr S Roy Choudhury, Department of Biological Anthropology, University of Cambridge, Pembroke Street, Cambridge CB2 3DZ, UK. Tel: + 44781748 0674; Fax: + 44122333 5460; E-mail: s.roy.choudhury.98@cantab.net

Received 25 October 2004; revised 26 July 2005; accepted 4 August 2005; published online 21 September 2005 access to benefits developed from research studies. ${ }^{2}$ Thus, the potential for research sponsored by developed countries to exploit populations in developing countries is a topic of concern. ${ }^{3}$ Applying appropriate research standards in developing countries and establishing collaborative, biomedical research between developed and developing countries remains controversial. ${ }^{3,4}$ Utilising established guidelines is paramount for successful health investigations in developing countries. This article summarises international and national UK guidelines for designing and implementing nontherapeutic genetic studies with human subjects in developing countries. For this review, a human subject is defined as a living individual for whom a researcher obtains data or identifiable private information. ${ }^{5}$ This definition will be extended to include any biological samples obtained from the subject. 


\section{International and national ethical guidelines for} human biomedical research

The Nuremberg Code was created in 1947 in response to global outrage against human experimentation conducted during World War II. ${ }^{6}$ These guidelines set the framework for all future ethical and legal concerns ${ }^{7}$ by protecting the integrity of research participants. ${ }^{1}$ In 1964, the World Medical Association (WMA) released the Declaration of Helsinki (DH), which emphasised principles for human biomedical research. ${ }^{8}$ The Declaration has since provided the basis for detailed international and national guidelines. ${ }^{1}$ Later, the Council for International Organizations of Medical Sciences (CIOMS) and the World Health Organization (WHO) proposed guidelines for health research sponsored by developed countries and conducted in developing countries ${ }^{9,10}$ (Table 1). Recently, international bodies such as UNESCO and governments such as the House of Commons (UK) have established specific guidelines for collecting biological samples. ${ }^{11,12}$

Many developed and developing countries have utilised international guidelines to form national guidelines. Some countries have extensive guidelines, while others do not. ${ }^{1}$ In the UK, the Medical Research Council (MRC), the Wellcome Trust and the Nuffield Council on Bioethics (NCB) have established guidelines for human participation in research. In most countries, ethical guidelines are not legally enforced, although some foundations enforce ethical adherence for acquiring grants. Other countries have voluntary guidelines or codes that bind certain researchers or signatory bodies. ${ }^{1}$ In some developing nations, the capacity to create national guidelines may not exist or may be deemed unnecessary. Unfortunately, researchers in developed and developing countries may be unaware of guidelines they need to consider. ${ }^{1}$ Although few guidelines exist for researchers working in specific communities, $^{4}$ guidelines for conducting research in aboriginal communities are available. ${ }^{13}$ However, applying these guidelines, or developing new guidelines, in different communities remains problematic. ${ }^{4,13}$

\section{Suitability of research in the developing country}

There are many clear guidelines concerning 'therapeutic research' which has direct health benefits for participants (eg, testing a vaccine). However, guidelines are more ambiguous for nontherapeutic studies, which do not have direct benefits for participants but may have future benefits for others. Since many human genetic studies are nontherapeutic, clear guidelines are essential.

Nontherapeutic research involving humans should meet the following criteria. First, the research is necessary to accomplish an important goal. Second, information cannot be obtained in other ways. Third, foreseeable benefits must outweigh potential risks to participants and risks should be as low as possible. Fourth, qualified researchers will conduct the study. ${ }^{14}$ Fifth, the study will be based on generally accepted scientific principles and adequate planning, field-testing and experimentation..$^{8,10,15}$ Finally, the study must have a valid project design. ${ }^{15}$

The CIOMS guidelines state that research should not be conducted in developing countries if the research could be undertaken in developed communities and it should be responsive to health needs and priorities of the study community. ${ }^{10}$ Additionally, researchers from developed

Table 1 Key international and European guidelines on human biomedical research (adapted from NCB, 2002) ${ }^{1}$

\begin{tabular}{|c|c|c|}
\hline Year & Organisation & Guidelines \\
\hline 1947 & Nuremberg War Crimes Tribunal & Nuremberg Code \\
\hline 1948 & United Nations General Assembly & The Universal Declaration of Human Rights \\
\hline 1964 & World Medical Association (WMA) & Declaration of Helsinki Revised: 1975, 1983, 1989, 1996, 2000 \\
\hline 1991 & $\begin{array}{l}\text { Council for International Organizations of Medical } \\
\text { Sciences (CIOMS) and WMA }\end{array}$ & $\begin{array}{l}\text { International Guidelines for Ethical Review of Epidemiological } \\
\text { Studies }\end{array}$ \\
\hline 1993 & CIOMS/WMA & $\begin{array}{l}\text { International Guidelines for Biomedical Research Involving } \\
\text { Human Subjects Revised: } 2002\end{array}$ \\
\hline 1995 & World Health Organisation (WHO) & $\begin{array}{l}\text { Guidelines for Good Clinical Practice for Trials on Pharmaceutical } \\
\text { Products }\end{array}$ \\
\hline 1996 & International Conference on Harmonisation & Harmonised Tripartite Guideline on Good Clinical Practice \\
\hline 1996 & The Council of the Human Genome Organisation (HUGO) & Statement on the Principled Conduct of Genetics Research \\
\hline 1997 & UNESCO & Universal Declaration of the Human Genome and Human Rights \\
\hline 1997 & Council of Europe & Convention on Human Rights and Biomedicine \\
\hline 1998 & HUGO & Statement on DNA Sampling: Control and Access \\
\hline 2000 & European Union & Charter of Fundamental Rights of the European Union \\
\hline 2000 & UNAIDS & Ethical Considerations in HIV Preventive Vaccine Research \\
\hline 2000 & WHO & $\begin{array}{l}\text { Operational Guidelines for Ethics Committees that Review } \\
\text { Biomedical Research }\end{array}$ \\
\hline 2000 & HUGO & Statement on Benefit-Sharing \\
\hline 2002 & Council of Europe Steering Committee on Bioethics & $\begin{array}{l}\text { Proposal for an Instrument on the use of Archived Human } \\
\text { Biological Materials in Biomedical Research }\end{array}$ \\
\hline 2003 & UNESCO & International Declaration on Human Genetic Data \\
\hline
\end{tabular}


countries should not take advantage of the relative inability of low-resourced countries, or vulnerable populations, by conducting research inexpensively and avoiding regulations of developed countries. Studies should lead to improvement for low-resourced countries or communities or, at least, the community should not be left in a poorer condition. $^{16}$

\section{Responsibilities of the researcher Project review}

Scientific and ethical qualities of projects involving human participants should be scrutinised by senior clinicians or researchers. ${ }^{17}$ Predictable risks compared with benefits should be carefully evaluated. ${ }^{8}$ Researchers should submit proposals to one or more scientific and ethical review committees. ${ }^{10}$ For externally sponsored research in developing countries, the proposal should be submitted to ethics committees in the sponsoring and host countries. Unfortunately, this may not always be feasible. First, some countries lack ethics committees or lack qualified committee members. ${ }^{10}$ Second, the study community may not have committee representatives. Third, once the proposal has been reviewed in the sponsor's country, ethics committees in developing countries may be pressured into agreeing with the committee from the sponsoring country, particularly when reviewing research of which they have limited experience. ${ }^{1}$ The DH suggests that the committee conforming most closely to the laws and regulations of the country where the research will be performed is the most appropriate committee to evaluate a proposal. ${ }^{8}$ Disagreements may arise between committees and resolving conflicts remains challenging. For example, if the ethics committee from the sponsoring country does not support the study, the project cannot be funded. If the ethics committee from the host country does not approve the study, the project cannot be conducted. ${ }^{1}$

\section{Protection and respect of participants}

In nontherapeutic research, the researcher must protect the life and health of all participants. The interests of science and society should never take precedence over the participant's well-being. ${ }^{8}$ The participants' autonomy (the ability to act independently or to have freedom to do so ${ }^{18,19}$ ) should be respected. ${ }^{8,10}$ However, rights to autonomy tend to vary by sex, age, status, ethnicity, education and economic participation in different societies. ${ }^{20}$ The study should have minimal impact on the participant's personality, physical and mental integrity ${ }^{8}$ and the investigation should be discontinued if it proves harmful. A participant should be a volunteer and face risks that are as low as possible, even if future benefits to others may be extensive. ${ }^{21}$ Unfortunately, determining risk levels is not straightforward. Researchers need to explain the benefits and risks of participation to subjects and state that a subject's participation is for potential future benefits for others. ${ }^{8}$ Researchers must dedicate time with participants to alleviate 'therapeutic misconception'. This is the belief that the research is a promising treatment for the participant's benefit. ${ }^{22}$ This is particularly relevant for human genetic studies, which require analysis of gene expression and hereditary patterns in families and, consequently, may not have direct or immediate health benefits for participants.

\section{Protection and respect of the community}

There is also growing public concern for community protection in research. ${ }^{23}$ Current guidelines may be too individualistic and fail to protect families or communities. ${ }^{13}$ Communities represent diverse human associations $^{23,24}$ and cultural misunderstandings may affect the project's progress or results. Importantly, a community may have multiple, and possibly conflicting, interpretations of its own traditions and values. ${ }^{13}$ The researcher must be respectful of social, cultural and political differences between the researcher and community, as well as within the community itself. ${ }^{4,15}$ Discussions with local community members, experienced researchers, interpreters and assistants may aid researchers in understanding social and cultural issues. ${ }^{1}$ While community protection in research remains controversial, the researcher can provide protection at all stages, from study initiation to publication of results. ${ }^{13}$

\section{Providing information to participants}

To request participation in nontherapeutic studies, basic information must be provided to the individual. This includes disclosing the project's aims, methodology, duration of subject participation, foreseeable benefits or risks, safeguards for confidentiality, funding sources and institutional affiliations. ${ }^{8}$ If biological samples are collected, participants must be given information on collecting, processing and storing samples. They should be told how the sample will be used, how research results could impact their personal interests ${ }^{25}$ and potential future use of samples. The researcher must clearly state that the participant is free to abstain, or withdraw, from the study at any time. ${ }^{8}$ This should include the possibility that his/her sample be withdrawn/destroyed. ${ }^{26}$ This information should be conveyed accurately, concisely and clearly, in an appropriate social and cultural context for the participant. ${ }^{1}$ Information can be conveyed orally, or written, in a language that is understandable to participants. ${ }^{10}$

Participants in genetic studies in developing and developed countries may find terms such as 'genetic research' incomprehensible. ${ }^{1}$ Important terminology, such as 'samples' and 'DNA,' can be misinterpreted and have negative connotations. ${ }^{27}$ Incorrectly translated terms can also cause confusion. Therefore, an iterative process of translation and back-translation is required. ${ }^{1}$ Importantly, many 
languages do not have words for some scientific concepts. For example, in a genetic study with Nigerians, the terms 'genotyping' and 'candidate genes' were not understood since there is no local term for 'gene' ${ }^{28}$ Previous studies in developing countries demonstrate that these words can be successfully explained ${ }^{1}$ and it is the researcher's responsibility that these words are understood. If the researcher cannot speak the local language, interpreters should have sufficient scientific and medical knowledge to explain terminology. $^{25}$ Finally, researchers should encourage participants to ask questions to alleviate concerns and misconceptions. ${ }^{1}$ Once potential subjects understand the information, researchers can request their participation.

\section{Obtaining informed consent}

Researchers must obtain voluntary informed consent from subjects. ${ }^{10}$ Informed consent is based on the principle that competent individuals are entitled to choose freely whether or not to participate in research. Informed consent protects the individual's freedom of choice and autonomy. ${ }^{1}$ While seeking consent, the researcher must not deceive or intimidate the participant. Consent can only be sought after the individual has adequate knowledge of the facts and consequences of participation and has had sufficient opportunity to ask questions and consider participation.

Controversies arise when adults who are not capable of informed consent are involved in biomedical studies. In these cases, the risks associated with the study must be even lower. That is, the risk posed from nontherapeutic research should not be greater than a routine medical or psychological examination. Determining levels of acceptable 'risk' remains controversial. ${ }^{10}$ Challenges also arise when obtaining informed consent for research involving children. Generally, children should not be involved in research that could be conducted with adults. However, a child can be involved in a study if the purpose is to obtain knowledge relevant to children's health needs. For children under the age of $14,{ }^{29}$ or adults incapable of consent, their assent should be sought to the extent of their capabilities and a parent or legal guardian must give proxy consent. The individual's refusal to participate must always be respected. ${ }^{8,10}$

In many developing countries, respect for the family and community are as important, if not more so, than individual autonomy. ${ }^{13}$ It may be necessary to obtain consent from community leaders, or the community as a whole, before seeking individual consent. ${ }^{10,30}$ Yet, it may be unclear who represents a community and conflict may arise when there is more than one individual/group representing the community's interests. ${ }^{13}$ Difficulties may also arise when community and individual interests conflict. For example, the community may withdraw consent but individuals may wish to continue. ${ }^{23}$ In other societies, the husband's consent is required for inclusion of his wife and/or offspring in research. Notably, the husband's, or community, consent can be supplementary, but not a replacement, for individual consent. ${ }^{10,13,23}$

Consent can be indicated verbally or by voluntary actions. ${ }^{10}$ Any procedure selected for obtaining consent must be authorised by local ethics committees. ${ }^{9}$ Generally, the participant signs a form as evidence that information has been provided and consent has been granted. ${ }^{25}$ However, an ethics committee may waive the requirement of signed consent forms if the research carries very low risks ${ }^{10}$ or when signing forms may be inappropriate for the community. For example, written consent forms may be unsuitable in communities where illiteracy is widespread. ${ }^{31}$ Asking participants to sign any document which they cannot read, or fully comprehend, can be threatening to people who only sign, or use thumbprints, for marriage certificates or other life documentation. Some literate participants may not wish to sign forms due to fears of signing away rights or of adverse repercussions. ${ }^{1,32}$ If the participant is not required to sign a form, the researcher can sign a form stating that appropriate information was given and verbal informed consent received. Verbal consent can be observed by an independent witness or be recorded on audio-tape. ${ }^{1}$

Obtaining informed consent is dependent on the communication between researchers and participants. The researcher should respect the limits of the participant's understanding and capacity to deal with difficult information, allowing time for reflection and questioning. For example, participants may have little understanding of biological processes, or have different beliefs about causes of disease, which make it more difficult to comprehend scientific information. ${ }^{25}$ Consent forms can also cause confusion. Common flaws of consent forms are the overemphasis of potential benefits, the understatement of potential risks and the complex and technical language. ${ }^{22}$ In the US, forms requiring very high reading levels, were not understood by subjects. ${ }^{33}$ A genetic study on respiratory distress syndrome revealed that $97 \%$ of nonconsenting families did not participate due to fears related to consent form language. ${ }^{34}$

Importantly, once consent is given it is not necessarily enduring. For example, a subject may choose to withdraw from the study. Researchers should maintain subject consent in long-term studies by providing current project information and renewing consent if study procedures alter. ${ }^{10}$ Thus, obtaining informed consent requires careful explanations, clear forms and trained staff. To evaluate the suitability and subjects' understanding of the consent process, consent procedures can be tested in preliminary studies.

\section{Inducements for study participation}

The Council of Europe states that the human body and its parts should not give rise to financial gain. ${ }^{2,35}$ Thus, 
participants should not be offered excessive financial inducements to participate in a study ${ }^{10}$ or to donate biological samples. ${ }^{14,25}$ Participants (especially those in nontherapeutic studies) may be reimbursed for inconvenience or time spent on the project. ${ }^{10,25}$ An ethics committee must approve any compensation. ${ }^{10}$ Acceptable compensations include travel expenses, payment for inconvenience and work lost, food, photographs or film, health care during the project or community health interventions. ${ }^{1}$ Compensation should not be so extensive to induce individuals to consent against their better judgment. The dividing line between inducement and benefit is fine. The greater the inducement, the greater the risk individuals may ignore their concerns about the study. ${ }^{1}$ Additionally, standards of acceptable compensation differ according to different socio-cultural and economic conditions. ${ }^{36}$

\section{Special considerations for genetic studies}

There are additional considerations when conducting nontherapeutic genetic studies, including the public's perception of genetics and the collection, transport and storage of biological samples. While these considerations often arise during studies, they should be considered in the planning stages.

\section{Perceptions of human genetic studies}

In 2000, the Wellcome Trust and MRC investigated public perceptions of human genetic research and collection of biological samples in the UK. ${ }^{27}$ For most people surveyed $(n=150)$, medical research was considered worthwhile. However, participants were less familiar and more uncomfortable about genetic research. Genetic research was perceived as less purpose-driven and associated with investigations of the body, rather than diseasespecific work. Some believed that genetic research was initiated for its own sake, or for the benefit of scientists, rather than for the general good of society. Improved understanding of genetic concepts led to more positive reactions towards genetic research. Associations with pharmaceutical/biotechnological companies caused concern, but nonprofit projects were more acceptable and credible. $^{27}$

Human genetics is distinct from other research. Genetic information from a participant provides information about his/her relatives, or a whole group, who may or may not be study participants. ${ }^{10,37}$ Human genetic data can predict genetic predispositions and may contain important information not known at the time of sample collection. ${ }^{11}$ Genetic information may trigger discrimination or psychosocial problems for those with common ancestry, even though family members may not have been informed of, or consented to, participation. ${ }^{38,39}$ Moreover, some people fear that genetic information can be used to limit or deny access to health insurance, job opportunities or cause emotional stress. ${ }^{40}$ In a genetic study of respiratory distress syndrome, $79 \%$ of nonconsenting families did not participate due to fears of denial for health insurance and employment. ${ }^{34}$ Notably, UNESCO suggests that individual genetic data should not be disclosed, or made accessible, to third parties such as employers or insurers. $^{11}$

Most genetic studies involve genotyping participants for polymorphisms that are linked, or associated, with disease susceptibility. Thus far, there is no consensus on when, and under what conditions, it is appropriate to feedback results to participants. ${ }^{16}$ Where there is a high risk of developing, or transmitting, a serious disorder and prevention/treatment is available, many guidelines suggest that genetic information should be reported to participants. However, whether this information is conveyed to nonparticipant family members, remains controversial. ${ }^{18,41-43}$ WHO suggests that immediate relatives should have access to genetic information of research participants to ascertain their own health status. ${ }^{18}$ This recommendation, in turn, can lead to contentious confidentiality issues for participants in genetic studies.

\section{Use of human biological samples}

Human biological samples are important DNA sources for research. ${ }^{27}$ Respecting human dignity and protecting human rights and fundamental freedoms must be maintained during collection, processing, use and storage of samples and genetic data. ${ }^{11}$ In research, the interests and welfare of the participants and their samples must prevail over the interests of society or science. ${ }^{44}$ Thus, genetic studies that utilise samples must be carefully designed and implemented.

The aims of the research often determine whether or not biological samples and personal data are connected to individual subjects. ${ }^{14}$ Coded samples are concealed by a code, but it is possible for the researcher to break the code and identify subjects. Anonymised samples have had identification removed. Linked anonymised samples are fully anonymous to the researcher, but contain information which allows some independent body responsible for granting privacy to identify subjects. Unlinked anonymised samples contain no information for identifying subjects. Researchers must first decide whether research results should be linked to subjects or not. This must be approved by an ethics committee and clearly explained to participants before seeking consent. ${ }^{16}$ When samples are not fully anonymised (for valid clinical or research reasons), the researcher should assure participants that their identity will be protected by secure coding and restricted data access. ${ }^{10}$

For many genetic studies, unlinked anonymised samples provide substantial information. ${ }^{16}$ Absolute confidentiality is maintained and samples may be used in future studies. ${ }^{26}$ 
In these cases, specific results from genetic analyses cannot be reported to participants and will, therefore, have no impact on participants. However, irreversibly breaking the link between samples and participants can decrease the potential value of the sample,$^{26,42,45}$ since it is impossible to add follow-up data. ${ }^{45}$ By retaining identifiers and requiring further consent, research might be more effective and participants can be notified if a therapeutic option becomes available. ${ }^{26}$

In some countries, a license may be required to collect biological samples for biomedical/genetic research. In the UK, the Human Tissue Authority regulates sample collection, which requires approval from an ethics committee. ${ }^{25}$ Without a license, researchers may face fines or imprisonment. ${ }^{12}$ Recommendations regarding archived samples, such as surplus clinical material, or samples collected when consent was not required, are ambiguous. ${ }^{14,25}$ Some guidelines suggest that ethics committee approval is essential for new research using surplus, or archived, samples. ${ }^{25}$ Other guidelines suggest that using anonymous or unlinked anonymised archived samples does not require further ethics committee approval since these samples are not classified as human subject research. ${ }^{5,14,46}$ In many cases, it may not be possible, or practical, to seek consent from donors. ${ }^{16}$ Thus, archived samples collected in developing countries without consent or ethics committee approval could be potentially used for genetic studies conducted by researchers from developed countries. This potential for sample exploitation needs to be further addressed in ethical guidelines.

The type of sample collected may also influence participation rates. Obtaining blood samples may reduce participation, as opposed to collecting less-invasive samples, such as hair or buccal cells. A recent clinical study in India revealed that most patients withheld consent since they did not want to give blood. ${ }^{47}$ Researchers should be aware of cultural or religious differences in the significance attached to the body, or body parts, before approaching subjects. $^{16}$

The general consensus is that informed consent must be obtained to collect biological samples. ${ }^{14,44,45}$ However, there is disagreement regarding cases where a subject withdraws consent during a study. One suggestion is that the participant's genetic data and linked samples should no longer be used ${ }^{11,26}$ and participants should be given the opportunity to have their samples destroyed. ${ }^{26}$ If samples are unlinked anonymised, then sample and data withdrawal is not possible. Additional guidelines are needed to maintain flexibility for identification of samples and data. ${ }^{44}$

Genetic data or samples collected for one study should not be used for purposes which are incompatible with the original consent. ${ }^{11}$ Informed consent forms in genetic research often do not explain that samples may be retained for future use, or that samples are sometimes used by other researchers. ${ }^{48}$ Thus, researchers should reasonably anticipate future plans to use specimens and consider whether secondary use is within the scope of their study. In this case, a two-step procedure may be followed: obtaining consent for sample use in the current study and obtaining consent for sample storage, transfer and future use. ${ }^{25}$ Difficult ethical issues are raised when biological samples are used for purposes not foreseen during sample collection. ${ }^{16}$ With linked anonymised samples, researchers should seek new ethics committee approval and re-contact subjects to obtain consent for research projects not originally foreseen. ${ }^{16,26}$ Currently, with unlinked anonymised samples no new consent is required. ${ }^{16}$

Storage of data or samples should also be negotiated with the study community. ${ }^{13}$ Subjects are more likely to participate in a project if sample collection and storage is overseen by an independent body, ideally including a known public figure and members of the study community. ${ }^{27}$ Guidelines offer different recommendations for sample storage. The MRC suggests that the researcher's host institution is the most appropriate body for formal responsibility for samples. ${ }^{45}$ Other guidelines suggest that samples should be stored within the study community, while others do not discuss storage conditions. ${ }^{13}$

\section{Benefit sharing}

UNESCO and HUGO suggest that benefits from human genetic data, or samples collected for research, should be shared with the international community. ${ }^{11,49}$ For reasons of justice, UNESCO encourages international dissemination of scientific knowledge generated from genetic studies between developed and developing countries. ${ }^{11}$

For genetic research with either no results or profits, HUGO recommends that participants are thanked and provided information about the research outcomes. ${ }^{49}$ Information could be conveyed by post or a website. ${ }^{25}$ Research participants appreciate feedback on what researchers discovered or achieved. This sustains the participant's interests and assures them that their involvement was worthwhile. ${ }^{27}$ A survey indicated that $48 \%$ of respondents $(n=1000)$ felt respected if they were notified each time their sample was used in a genetic study. ${ }^{50}$ Study communities could be more actively involved in dissemination and publication of results, ${ }^{13}$ but the practicality of this remains debatable. More controversially, HUGO suggests that immediate benefits (ie, medical care, technology transfer or contribution to the local infrastructure) could be provided by nonprofiting genetic studies. ${ }^{49}$ Once again, the feasibility of these suggestions remains contentious.

If knowledge gained from research in a developing country is used to benefit other populations that can afford the new product, the research could be characterised as exploitive. Thus, products arising from a project should 
be made available to the study community. ${ }^{10,49}$ More controversially, HUGO suggests that profit-making genetic endeavours should dedicate a percentage of their annual net profit to healthcare infrastructure and/or humanitarian efforts. ${ }^{49}$ The CIOMS guidelines also suggest that externally sponsored research should contribute to national, or local, capacity to conduct biomedical research in the host country. ${ }^{10}$ The feasibility of providing such extensive benefits beyond the immediate study is controversial. It has also been suggested that reasonable availability of benefits should not be imposed as an ethical requirement for research in developing countries without consent from the host country. ${ }^{3}$ When nontherapeutic genetic studies, yield only scientific knowledge, rather than a commercial product, considerations of product availability may not be paramount. Nevertheless, there must be assurance that the scientific knowledge would be beneficial for the study population. ${ }^{10}$
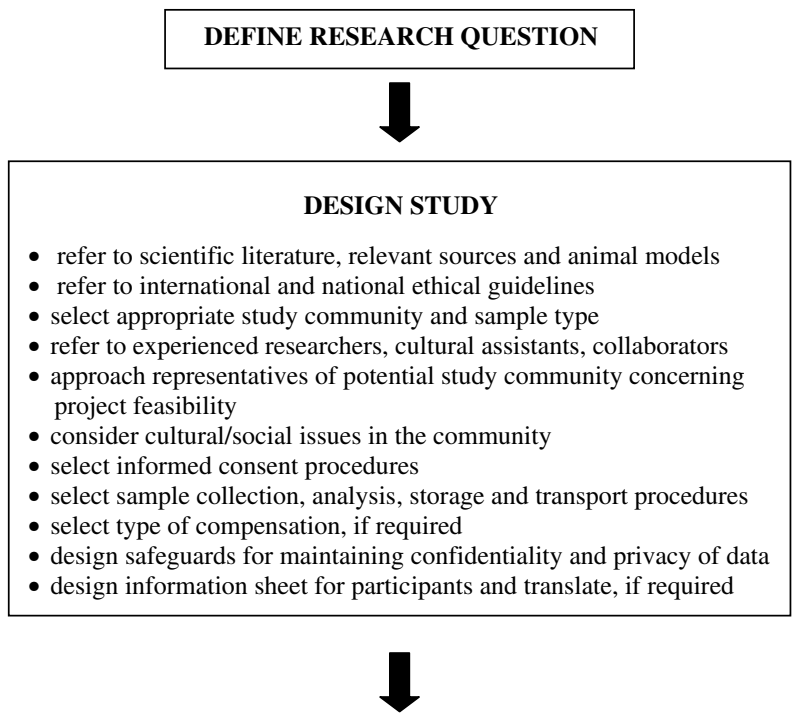

SUBMIT STUDY PROPOSAL TO ETHICS COMMITTEES

- submit to committees in both sponsoring and host countries

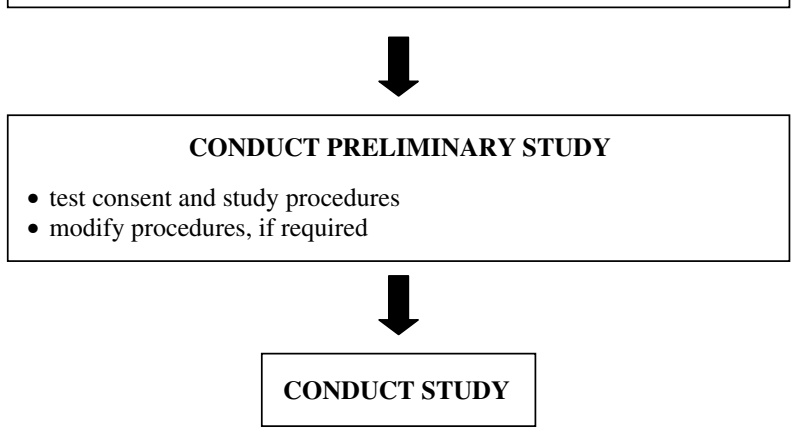

Figure 1 Key steps for conducting human genetic studies in developing countries.

\section{Conclusion}

This article has reviewed key international and UK-based ethical guidelines for researchers designing and implementing nontherapeutic genetic studies in developing countries. We have designed a flow-chart (Figure 1), based on the guidelines, for designing these studies. Researchers have specific responsibilities that include submitting proposals to ethics committees, protecting participants and communities, providing appropriate information to participants, obtaining informed consent and providing compensation to participants. Researchers must alleviate linguistic or cultural misunderstandings concerning the project by providing clear and precise information to participants. Finally, researchers must consider specific issues surrounding human genetic studies, including public perceptions of genetics, sample collection, storage and future use.

\section{Acknowledgements}

This work was supported by the Association of Commonwealth Universities, the British Council, the Harold Hyam Wingate Foundation, the Evans Fund (SRC) and the Wellcome Trust (LAK). We also gratefully acknowledge helpful comments from the two anonymous reviewers.

\section{References}

1 Nuffield Council on Bioethics: The ethics of research related to healthcare in developing countries. Nuffield Foundation, MRC \& Wellcome Trust, 2002.

2 Shapiro HT, Meslin EM: Ethical issues in the design and conduct of clinical trials in developing countries. N Engl J Med 2001; 345: $139-142$.

3 El Setouhy M, Agbenyega T, Anto F et al, Participants in the 2001 Conference on Ethical Aspects of Research in Developing Countries: Ethics. Fair benefits for research in developing countries. Science 2002; 298: 2133-2134.

4 Weijer C: Protecting communities in research: philosophical and pragmatic challenges. Camb Q Healthc Ethics 1999; 8: 501-513.

5 Office for Human Research Protections (OHRP): Guidance on Research Involving Coded Private Information or Biological Specimens 2004. (Accessed December 2004). http://www.hhs.gov/ohrp/ humansubjects/guidance/cdebiol.pdf.

6 Nuremberg Code; In: Duncan AS, Dunstan GR, Welbourn RB (eds): The Dictionary of Medical Ethics [revised ed]. New York: Crossroad, 1981.

7 Shuster E: Fifty years later: the significance of the Nuremberg Code. N Engl J Med 1997; 337: 1436-1440.

8 World Medical Association: The Declaration of Helsinki, ethical principles for medical research involving human subjects. Amended by the WMA 52nd General Assembly, Edinburgh, 2000.

9 Council for International Organizations of Medical Sciences (CIOMS): Ethics and Research on Human Subjects. International Guidelines. Proceedings of the XXVIth CIOMS Conference, Geneva, Switzerland. 5-7th February 1992, Switzerland: CIOMS, 1993.

10 Council for International Organizations of Medical Sciences (CIOMS): International Ethical Guidelines for Biomedical Research Involving Human Subjects. Switzerland: CIOMS, 2002, (Accessed December 2004). http://www.cioms.ch/frame_guidelines_nov_ 2002.htm.

11 UNESCO, United Nations Educational, Scientific and Cultural Organization: International Declaration on Human Genetic Data 2003. Document Code: SHS.2004/DECLAR.BIOETHIQUECIB/4. 
12 House of Commons UK: Human Tissue Bill. London: London Stationary Office, 2003.

13 Weijer C, Goldsand G, Emanuel E: Protecting Communities in research: current guidelines and limits of extrapolation. Nat Genet 1999; 23: $275-280$.

14 Council of Europe, Steering Committee on Bioethics (CDBI)Evans I, Roscam Abbing H: Proposal for an instrument on the use of archived human biological materials in biomedical research, 2002a, (Accessed February 2005), http://www.coe.int/T/E/Legal_affairs/Legal_co-operation/Bioethics/Activities/Biomedical_research/CDB1-INF(2002)5E.pdf.

15 Council of the Human Genome Organisation (HUGO): Statement of the Principled Conduct of Genetics Research 1996, (Accessed December 2004). http://www.gene.ucl.ac.uk/hugo/conduct.htm.

16 Medical Research Council: Report: interim guidelines. Research involving human participants in developing societies; in: $M R C$ (ed.): Ethical Guidelines for MRC-sponsored Studies. London: Medical Research Council, 1998.

17 Royal College of Physicians: Guidelines in the Practice of Ethics Committees in Medical Research Involving Human Subjects, 2nd edn., London: Royal College of Physicians, 1990.

18 WHO: Proposed international guidelines on ethical issues in medical genetics and genetic services. Report of a WHO meeting on ethical issues in medical genetics, Geneva, 15-16 December. Document code: WHO/HGN/GL/ETH/98.1, 1997.

19 Bunch WH: Informed consent. Clin Orth Rel Res 2000; 378: $71-77$.

20 de Sweemer-Ba C: Informed consent: protecting the vulnerable; In: Bankowski Z, Levine RJ (eds): Ethics and Research on Human Subjects: International Guidelines. Switzerland: CIOMS, 1993, pp 36-43.

21 Gillon R: Ethical review procedures: a developed countries' perspective; In: Bankowski Z, Levine RJ (eds): Ethics and Research on Human Subjects: International Guidelines. Switzerland: CIOMS, 1993, pp 70-87.

22 Macklin R: Understanding Informed Consent. Acta Oncologica 1999; 38: 83-87.

23 Weijer C, Emanuel EJ: Ethics. Protecting communities in biomedical research. Science 2000; 289: 1142-1144.

24 Weijer C, Miller PB: Protecting communities in pharmacogenetic and pharmacogenomic research. Pharmacogenomics J 2004; 4: $9-16$.

25 Medical Research Council: Report: human tissue and biological samples for use in research. Operational and ethical guidelines. Medical Research Council, 2001.

26 Recommendations of the European Society of Human Genetics: Data Storage and DNA banking for biomedical research: technical, social and ethical issues. Eur J Hum Genet 2003; 11 (Suppl 2): S8-S10.

27 Wellcome Trust \& MRC: Report: Public perceptions of the collection of human biological samples. Wellcome Trust \& MRC, 2000.

28 Marshall P: The Relevance of Culture for Informed Consent in U.S. Funded International Health Research; In: Ethical and Policy Issues in International Research: Clinical Trials in Developing Countries, Volume II: Commissioned Papers and Staff Analysis. NBAC, Bethesda, MD: National Bioethics Advisory Commission, 2001, pp C1-C38.

29 Wendler D, Shah S: Should children decide whether they are enrolled in nonbeneficial research? Am J Bioeth 2003; 3: 1-7.

30 Foster MW, Eisenbraun AJ, Carter TH: Communal discourse as a supplement to informed consent for genetic research. Nat Genet 1997; 17: $277-279$.
31 Preziosi MP, Yam A, Ndiaye M, Simaga A, Simondon F, Wassilak SG: Practical experiences in obtaining informed consent for a vaccine trial in rural Africa. N Engl J Med 1997; 336: 370-373.

32 Coulibaly D, Msellati P, Dedy S, Welffens-Ekra C, Dabis F: Attitudes and behaviour of pregnant women towards HIV screening in Abidjan (Ivory Coast) in 1995 and 1996. Sante 1998; 8: 234-238.

33 White LJ, Jones JS, Felton CW, Pool LC: Informed consent for medical research: Common discrepancies and readability. Acad Emerg Med 1996; 3: 745-750.

34 Hamvas A, Madden KK, Nogee LM et al: Informed consent for genetic research. Arch Pediatr Adolesc Med 2004; 158: 551-555.

35 Council of Europe: Convention of Human Rights and Biomedicine 1997, (Accessed February 2005). http://conventions.coe.int/ treaty/en/treaties/html/164.html.

36 Working Group A: Informed consent; In: Bankowski Z, Levine RJ (eds): Ethics and Research on Human Subjects: International Guidelines. Switzerland: CIOMS, 1993, pp 56-61.

37 Austin MA: Ethical issues in human genome epidemiology: a case study based on the Japanese American family study in Seattle, Washington. Am J Epidemiol 2002; 155: 585-592.

38 Clayton E: Panel comment: why the use of anonymous samples for research matters. J Law Med Ethics 1995; 23: 375-377.

39 McPherson E: Ethical implications of the human genome diversity project. Nursing Connections 1995; 8: 36-43.

40 Reilly PR, Boshar MF, Holtzman SH: Ethical issues in genetic research: disclosure and informed consent. Nat Genet 1997; 15: $16-20$.

41 President's Commission for the Study of Ethical Problems in Medicine and Biomedical and Behavioural Research: Screening and Counselling for Genetic Conditions. Washington, DC: US Government Printing Office, 1983.

42 HUGO International Ethics Committee: Statement of DNA Sampling 1998, (Accessed February 2005). http://www.hugointernational.org/hugo/sampling.html.

43 Hakimian R: Disclosure of Huntington's disease to family members: the dilemma of known but unknowing parties. Genet Test 2000; 4: 359-364.

44 Council of Europe, Steering Committee on Bioethics (CDBI), Evans I, Roscam Abbing H: Draft Explanatory Report to the proposal for an instrument on the use of archived human biological materials in biomedical research 2002b, (Accessed February 2005). http://www.coe.int/T/E/Legal_affairs/Legal_co-operation/Bioethics/ Activities/Biomedical_research/CDB1-INF(2002)6E.pdf.

45 Medical Research Council: Personal information in medical research. MRC ethics series. Medical Research Council, 2000.

46 Nationaler Ethrikrat: Biobanken fur die Forshung. Stellungnahme. Berlin, 2004, (Accessed February 2005) http://www.ethikrat.org/ themen/pdf/Stellunnahme_Biobanken_04-03-17.pdf.

47 Gitanjali B, Raveendran R, Pandian DG, Sujindra S: Recruitment of subjects for clinical trials after informed consent: does gender and educational status make a difference? J Postgrad Med 2003; 49: 109-113.

48 Weir RF, Horton JR: DNA banking and informed consent. Pt 1. IRB 1995; 17: 1-3.

49 Council of the Human Genome Organisation (HUGO): Statement on benefit-sharing 2000, (Accessed December 2004). http://www. gene.ucl.ac.uk/hugo/benefit.html.

50 Hoeyer K, Olofsson BO, Mjorndal T, Lynoe N: Informed consent and biobanks: a population-based study of attitudes towards tissue donation for genetic research. Scand J Public Health 2004; 32: $224-229$ 